\title{
UTILIDADE SOCIAL NA PERCEPÇÃO DOS USUÁRIOS DE ORGANIZAÇÕES DA SOCIEDADE CIVIL: PRIMEIRAS ANÁLISES A PARTIR DE UMA REDE DE ECONOMIA SOLIDÁRIA NA BAHIA-BRASIL
}

\author{
SOCIAL UTILITY FROM THE PERSPECTIVE OF BENEFICIARIES OF ORGANIZATIONS OF CIVIL SOCIETY: \\ INITIAL ANALYSES BASED ON A NETWORK OF SOLIDARITY ECONOMY IN BAHIA-BRAZIL
}

\section{UTILIDAD SOCIAL EN LA PERCEPCIÓN DE LOS USUARIOS DE ORGANIZACIONES DE LA SOCIEDAD CIVIL: PRIMEROS ANÁLISIS A PARTIR DE UNA RED DE ECONOMÍA SOLIDARIA EN BAHIA-BRASIL}

\author{
LAERSON MORAIS SILVA LOPES \\ Universidade Federal da Bahia - Brasil \\ laerson.lopes@ufba.br \\ ARIÁDNE SCALFONI RIGO \\ Doutora \\ Universidade Federal da Bahia - Brasil \\ ariadne.rigo@ufba.br \\ JEOVÁ TORRES SILVA JÚNIOR \\ Doutor \\ Universidade Federal do Cariri - Brasil \\ jeova.torres@ufca.edu.br \\ Submetido em: 29/11/2017 \\ Aprovado: 22/06/2018
}

Doi: alcance.v25n1(Jan/Abr).p38-60

\begin{abstract}
RESUMO
Neste estudo, discutiu-se o processo de avaliação do resultado das ações de organizações da sociedade civil, aqui resignificada como "utilidade social", considerando que essa avaliação é influenciada por vários aspectos. Nesse intuito, identificaram-se as dimensões da utilidade social apontadas pela literatura relevante, confrontandoas por meio de uma primeira aproximação empírica concernente à percepção dos beneficiários de uma rede de organizações da sociedade civil localizada na Bahia. Para instrumentalizar essa confrontação, foi construído um modelo de análise, com as dimensões da utilidade social e as suas variáveis instrumentais, a partir dessa literatura relevante. Na etapa empírica da pesquisa, foi utilizado como instrumento de pesquisa um questionário estruturado, considerando as variáveis do modelo de análise, e esse foi aplicado junto a moradores da localidade (possíveis beneficiários dessa rede). Os dados coletados foram tratados e analisados por meio de análise descritiva. Para eles, as organizações impactam, positiva e notadamente, as atividades de lazer e manifestações culturais (dimensão cultural); o emprego e o consumo (dimensão econômica); a participação eleitoral e a representação indireta da comunidade (dimensão política); a inovação social, a articulação institucional e 0 acesso a recursos tecnológicos (dimensão tecnológica); a consciência ambiental dos indivíduos (dimensão ambiental); e no acesso a serviços e o sentimento de pertencimento local (dimensão social). Tais achados demonstram que as organizações da rede de empreendimentos aqui analisadas, segundo a percepção de seus beneficiários, apresentam utilidade social nas seis dimensões apontadas por outros estudos, pelo menos nas variáveis anteriormente citadas de cada uma dessas dimensões. Estes resultados configuram-se como um primeiro passo na construção de uma metodologia e na sistematização de indicadores para a avaliação da utilidade social das organizações da sociedade civil.
\end{abstract}

Palavras-chave: Utilidade Social; Avaliação de Resultados; Organizações da Sociedade Civil. 


\section{ABSTRACT}

This study discusses the process of evaluating of outcomes of the actions of civil society organizations, here presented as "Social Utility", bearing in mind that this assessment is influenced by various aspects. We also identify the dimensions of social utility indicated by the relevant literature, comparing them through an initial empirical approach concerning the perceptions of the beneficiaries of a network of civil society organizations located in Bahia, Brazil. To instrumentalize this comparison, a model of analysis was constructed, with the dimensions of social utility and its instrumental variables, based on the relevant literature. In the empirical research stage, a structured questionnaire was used, considering the variables of the analysis model. This questionnaire was applied to inhabitants of the location (and possible beneficiaries of this network). The data collected were analyzed using descriptive analysis. For the interviewees, the organizations had had a positive and notable impact on the leisure activities and cultural events (cultural dimension); employment and consumption (economic dimension); electoral participation and the indirect representation of the community (political dimension); social innovation, institutional articulation and access to technological resources (technological dimension); environmental awareness of individuals (environmental dimension); and access to services and a sense of belonging to the local community (social dimension). These findings demonstrate that the organizations of the network of enterprises analyzed here, according to the perceptions of their beneficiaries, show social utility in the six dimensions pointed out by other studies, at least in the above-mentioned variables of each dimension. These results represent an initial step towards building a methodology and systematizing indicators for assessing the social utility of civil society organizations.

Keywords: Social Utility; Outcomes Evaluation; Civil Society Organizations.

\section{RESUMEN}

En este estudio, se discutió el proceso de evaluación de resultado en las acciones de organizaciones de la sociedad civil, resignificada como "utilidad social", considerando que esa evaluación es influenciada por varios aspectos. En este sentido, se identificaron las dimensiones de la utilidad social apuntadas por la literatura relevante, enfrentándolas por medio de una primera aproximación empírica concerniente a la percepción de los beneficiarios de una red de organizaciones de la sociedad civil ubicada en Bahía. Para instrumentalizar esa confrontación, fue construido un modelo de análisis, con las dimensiones de la utilidad social y sus variables instrumentales, a partir de esta literatura relevante. En la etapa empírica de la investigación, fue utilizado como instrumento de investigación un cuestionario estructurado, considerando las variables del modelo del análisis y este, fue aplicado a los habitantes de la localidad (posibles beneficiarios de esta red). Los datos colectados fueron tratados y analizados por medio de análisis descriptivo. Para ellos, las organizaciones impactan, positiva y notablemente, las actividades de ocio y manifestaciones culturales (dimensión cultural); el empleo y el consumo (dimensión económica); la participación electoral y la representación indirecta de la comunidad (dimensión política); la innovación social, la articulación institucional y el acceso a recursos tecnológicos (dimensión tecnológica); la consciencia ambiental de los individuos (dimensión ambiental); y el acceso a servicios y el sentimiento perteneciente al lugar (dimensión social). Tales hallazgos demuestran que las organizaciones de la red de emprendimientos aquí analizadas, según la percepción de sus beneficiarios, presentan utilidad social en las seis dimensiones apuntadas por otros estudios, por lo menos en las variables anteriormente citadas de cada una de estas dimensiones. Estos resultados se configuran como un primer paso en la construcción de una metodología y en la sistematización de indicadores para la evaluación de la utilidad social de las organizaciones de la sociedad civil.

Palabras clave: Utilidad Social; Evaluación de Resultados; Organizaciones de la Sociedad Civil.

\section{INTRODUÇÃO}

Sobre a evolução da humanidade, grandes pesquisadores estiveram preocupados em estudar a relação do homem com os seus pares, bem como sua relação com o Estado, com o mercado e com o ambiente. Nesse cenário, os cidadãos por muito exerceram papel coadjuvante e essa inércia deriva da própria estrutura hegemônica daqueles que detêm o poder, os quais cooptam os possíveis "intelectuais orgânicos" para que contribuam para a estabilidade do sistema (GRAMSCI, 1968). 
Nesse contexto, o fortalecimento do mercado e a instauração e expansão do liberalismo econômico influenciaram sobremaneira a precarização das condições de trabalho e de vida em geral, inclusive em grandes nações ditas desenvolvidas. Porém, Laville (2014) afirma que esse sistema tem suas bases abaladas, processo iniciado a partir de 1960, quando os cidadãos começam a organizar-se com o fim de demandar a participação em outras esferas da vida social. Ele entende que, se por um lado a globalização, o aumento da competitividade e o avanço tecnológico dos meios de produção contribuem para o enfraquecimento da classe trabalhadora na busca por seus pleitos, por outro lado há um impulso nas práticas de associativismo, ou seja, para que essa classe se organize na luta por tais direitos.

França Filho (2004) explica que as iniciativas associativistas como essa surgem na Europa, especialmente na França, em resposta à crise da sociedade salarial, à escassez do trabalho convencional e à crise do Estado-Providência, o que demonstra os limites do Estado e do mercado para regular a atividade econômica e social, impulsionando o surgimento dessas organizações no mundo todo. As primeiras organizações desse tipo estão ligadas a intelectuais que transitaram por movimentos diversos: socialistas utópicos, anarquistas, cooperativistas, cristãos e socialistas (ROSSO, 1996; SINGER, 2002; GAIGER, 2003; QUIJANO, 2005; SANTOS; RODRÍGUEZ, 2005).

Em Matarandiba, lócus desta pesquisa, movimentos sociais também surgem em confrontação às pressões do capital, sobretudo às ações de uma empresa multinacional naquela região (SANTANA, 2011). Santana (2011) identifica vários movimentos: Clube das Mães; Sociedade Beneficente Amigos de Matarandiba - Sobema; Conselho Comunitário de Matarandiba - CCM; e Associação Comunitária de Matarandiba - Ascoma. Essas iniciativas surgem com a disposição de enfrentar as desigualdades sociais baseadas nos mais variados objetivos institucionais. 0 estabelecimento e 0 alcance dos objetivos institucionais se tornam, então, traduções dos objetivos comuns das populações locais. Sendo assim, o processo de organização resulta em organizações da sociedade civil em relação às quais se constrói uma expectativa de obtenção de resultados que satisfaçam as necessidades daqueles que, direta ou indiretamente, se sentem parte do processo. De modo geral, o que se espera dessas organizações é que elas sejam "úteis".

O termo "utilidade social" foi primeiramente utilizado de maneira efetiva na França, a partir do início da década de 1970. Nesse período, a abordagem se deu principalmente do ponto de vista fiscal. Essa perspectiva inicial tem sido examinada no contexto das abordagens específicas para determinadas redes e estruturas de natureza territorial, combinando empreendimentos da Economia Social e Solidária e organismos do poder público. Duclos $(2007$, p. 6) aponta que "a aparição oficial de utilidade social na França data da decisão de 1973 do Conselho de Estado em matéria fiscal"i que impôs às associações, desejosas de se beneficiar de isenção fiscal, a necessidade de provar que seus serviços não eram prestados pelo mercado ou que tinhamum custo inferior ao das organizações empresarias mercantis. Em suma, precisavam comprovar que eram mais "úteis" do que organizações de natureza mercantil.

Jany-Catrice et al. (2014, p. 4) complementam que, anteriormente a essa exigência, "as características estatutárias de organização sem fins lucrativos e de gestão desinteressada não eram consideradas - até então - como suficientes para permitir que as associações se beneficiassem de um regime especial de tributação. Esses acordos com o Conselho de Estado, então, foram decisivos". Conforme Gadrey (2004, p. 28), a partir dos acordos de 1973, as condições de não lucratividade e a gestão desinteressada e o reinvestimento dos excedentes na instituição foram consideradas insuficientes para a isenção de impostos. Assim, uma terceira condição foi adicionada: os usuários habituais dos serviços da instituição - no caso de pagarem pelos serviços desta, devem se beneficiar diretamente do propósito dessa gestão desinteressada, "seja porque ela realiza seus serviços em condições, inclusive de preço, consideravelmente mais vantajosas do que as oferecidas por empresas comerciais com um propósito semelhante, seja porque ela fornece serviços que não são normalmente fornecidos pelo mercado".

Assim, a partir do que se viu em Jany-Catrice et al. (2014), Gadrey (2004) e Duclos (2007), com essa distinção as associações francesas que se enquadravam nas três condições poderiam acessar uma contribuição específica - por serem portadoras de "utilidade social" - e, ao mesmo tempo, concorrer 
'naturalmente no mercado', mas com um distinto reconhecimento no seu modelo de atuação. Portanto, a noção inicial de utilidade social foi empregada pela dimensão do domínio fiscal.

Na década de 1980 o uso do termo se popularizou também para justificar o auxílio e as isenções concedidas pelo governo às associações no seu serviço para a sociedade civil, com destaque para aquelas organizações que atuavam junto aos desempregados e às pessoas com vulnerabilidades econômicas. Nesses termos, a utilidade social dessas associações foi considerada relevante por se constituir limitador das consequências negativas do desemprego para os trabalhadores. Nos anos seguintes, a interpretação da noção de utilidade social amplia-se. Em Duclos (2007, p. 7), consta que algumas instruções fiscais de 1998 e 1999, retomando a jurisprudência das decisões do Conselho de Estado nos anos anteriores, incluíram a utilidade social nos critérios de isenção fiscal para as associações que desenvolviam atividades econômicas, mesmo que operassem em um campo competitivo de mercado. Em outras palavras, uma associação cuja gestão é desinteressada e exerce uma atividade econômica em condições diferenciadas do setor privado lucrativo pode ser desonerada em nome da sua utilidade social, desde que a sua atividade corresponda a uma necessidade mal atendida pelo mercado e seja realizada em benefício de pessoas que justificam a concessão de benefícios especiais, dada a sua situação.

Dos anos 2000 em diante, o tema da utilidade social se consolida dentro do quadro legal francês, com sua incorporação - mesmo que com definições diferentes - em alguns decretos e leis nos anos de 2000, 2001 e 2002. Em 2004, surge o relatório coordenado por Jean Gadrey - L'utilité sociale des organisations de l'économie sociale et solidaire: une mise en perspective sur la base de travaux récents (A utilidade social das organizações de economia social e solidária: uma perspectiva a partir de recentes estudos, em livre tradução) -, que oferece uma síntese com base em 23 trabalhos de pesquisas, patrocinado pela Delegação Interministerial para a Economia Social da França. Nos anos seguintes se avolumam estudos e pesquisa sobre o tema de utilidade social em vários projetos de investigação coordenados por professores, pesquisadores ou órgãos do poder público. Em complemento, Offredi (2010, p. 37) expressa que o desafio recorrente por trás dos debates sobre utilidade social, na França, é aquele do critério a ser considerado que justificasse a especificidade das organizações de economia solidária, garantindo-lhes um espaço legítimo de intervenção na sociedade em relação ao setor mercantil e concorrencial.

Assim, para os poderes públicos, os critérios de utilidade social permitem o apoio às associações e justificam o apoio do Estado e da sociedade. Não obstante, em Perret (2010) encontra-se a melhor interpretação para esta discussão do significado e da origem da utilidade social, na França, vinculada aos aspectos fiscais. Segundo o autor, a utilidade social foi expressa preliminarmente no domínio do direito fiscal, para justificar as exonerações tributárias concedidas para certas associações sem fins lucrativos. Todavia, para além do aspecto fiscal, "o conceito de utilidade social é portador de um desafio a ser reconhecido: a utilidade social é o termo conveniente para exprimir uma forma de pagamento da dívida da sociedade em relação aos atores sociais que contribuem no mundo 'fora do mercado"' (PERRET, 2010, p. 45).

Nessa linha do domínio conceitual, Gadrey (2004, p. 41) faz uma reflexão sobre o que caracteriza e como pode evidenciar a utilidade social em um empreendimento. Para 0 autor, pode-se considerar como uma ação de utilidade social a atividade de uma organização que possua por finalidade constatável e por objetivo explícito contribuir para a coesão social (principalmente, a redução das desigualdades), fortalecer a solidariedade e a sociabilidade, e melhorar as condições coletivas de desenvolvimento sustentável (a educação, a saúde, o meio ambiente e a democracia). Cauquil (2010, p. 11-12) acrescenta a esta caracterização a perspectiva que utilidade social não é somente um conceito técnico, nem fatalmente utilitarista, nem redutível só à soma dos interesses particulares. Ela remete, em vez disso, segundo o autor, ao interesse geral ou à utilidade coletiva, tanto na esfera do empoderamento político quanto na mensuração técnica da ação.

A utilidade social, de fato, é uma 'convenção sociopolítica' submetida ao debate nas diversas partes interessadas, em "um processo de construção social, o qual assume a necessidade de precisar 
seus limites, contornos e de validar seus objetivos somente através de procedimentos democráticos" (DUCLOS, 2010, p. 70). Para subsidiar a compreensão do que seja uma "convenção sociopolítica" nesta construção da utilidade social em um empreendimento, Offredi (2010, p. 42) esclarece que é o conjunto das regras e de normas sociais de domínio cognitivo dos atores, que se apoiam em considerações de justiça social, em visão mais ou menos explícita e compartilhada entre eles.

Complementando esse viés interpretativo-conceitual, Offredi (2010, p. 35) compreende que "a utilidade social é ontologicamente ligada a questão das partes interessadas. É um termo ainda polissêmico e isto constitui toda a sua riqueza". A utilidade social é, nesse sentido, um tema evolutivo e conjuntural se definindo por um conjunto de indicadores não exclusivos, não acumulativos e não exaustivos um com os outros. Por sua vez, as entidades com utilidade social são aquelas nas quais as atividades estão orientadas para o interesse público com uma exclusividade de atuação que contribua para o bem comum. Pode-se, desde então, considerar a utilidade social como uma noção suscetível para introduzir uma nova forma de regulação da ação pública e das relações entre o Estado e a Sociedade Civil, fundada sob o imperativo da deliberação.

Nestes termos, a utilidade social é multidimensional, considerando que numa leitura atual, ela representa a capacidade de as organizações impactarem o contexto que atuam, tanto na dimensão econômica quanto em outras dimensões, tais como a social, a cultural ou a política (SILVA JR.; RIGO; PASSOS, 2015; SILVA JR., FRANÇA FILHO; RIGO, 2015; SILVA JR., 2016). Em uma perspectiva multidisciplinar, surge aquela que se mostra como a mais adequada abordagem e apelação, a denominada contribuição para o bem comum, que significa os aportes das organizações da sociedade civil em atuação coletiva e em prol do interesse público (JANY-CATRICE et al., 2014 p. 5).

Porém, a literatura demonstra que a avaliação dessa utilidade social é influenciada por vários aspectos e nuances. Utilizando o termo efetividade para expressar a capacidade de as organizações atingirem seus objetivos institucionais, Sowa, Selden e Sandfort (2004) discutem se a metodologia utilizada para essa avaliação deve considerar aspectos quantitativos, qualitativos ou multidimensionais. Alguns estudos avaliam os obstáculos, os estímulos e o rigor metodológico do seu processo (MITCHELL; BERLAN, 2016); outros investigam se as ações possuem impactos capazes de transformar o status quo ou se apenas resultam em conformação com o sistema (BENINI; BENINI, 2015); outros, ainda, analisam se as avaliações estão centradas em indicadores sólidos ou calcadas nos beneficiários (ASSUMPÇÃO; CAMPOS, 2011).

Procurou-se saber, com base na percepção de beneficiários, o quanto essas organizações são capazes de lhes serem útil. De modo direto, este trabalho objetivou confrontar dimensões da utilidade social apresentadas na literatura com a percepção dos beneficiários das organizações da sociedade civil na comunidade investigada. Para tanto: i) levantaram-se as dimensões sugeridas na literatura; ii) verificaram-se as dimensões de utilidade social por meio da percepção dos beneficiários; e iii) confrontaram-se as dimensões identificadas pela literatura com as percebidas por seus beneficiários.

Em sua tese, Kuyven (2016) estuda sobre esse processo de avaliação na percepção dos(as) sócios(as) de organizações, mas sugere que outros estudos avaliem os benefícios gerados para além dos beneficiários diretos, lacuna que se insere este estudo, que é o primeiro, mas um importante passo de um programa de pesquisa longo e mais amplo. Corroborando a importância dos beneficiários na avaliação dessas organizações, Santos (2016) aponta que os gestores analisados dão destaque aos beneficiários dos projetos, sendo eles os primeiros lembrados dentre os diversos stakeholders. Portanto, este estudo traz contribuições ao processo de avaliação dessas organizações, ao investigar a percepção de beneficiários e não apenas dos gestores ligados diretamente aos empreendimentos.

As primeiras organizações localizadas na comunidade estudada nessa pesquisa surgem em 2007 (SANTANA, 2011). Mas há um aumento nas suas áreas de atuação até os dias atuais, de modo que se propôs a avaliar a "utilidade social" de toda a rede local de organizações sociais. Por exemplo, Guimarães (2012) levantou que as principais mercadorias consumidas pela comunidade, entre elas 0 pão, são adquiridas de fornecedores de outra localidade. Mas a existência atualmente de uma padaria 
comunitária entre os empreendimentos da rede pode ter modificado este cenário, de modo que ela seja útil para a comunidade ao estimular o consumo local (dimensão econômica).

Demonstrar que essas organizações podem ser úteis, como no exemplo, é deveras importante. Além disso, Mitchell e Berlan (2016) afirmam que o melhor entendimento sobre a avaliação de organizações do tipo e sobre fatores que interferem nesse processo traz benefícios às mesmas, ajudando a demonstrar de maneira mais adequada o seu valor, aumentando sua legitimidade, suas chances de obter recursos e as possibilidades de atender aos seus beneficiários. Nesse contexto, a Lei $n^{0}$ 13.019/2014 (BRASIL, 2014) prevê que a avaliação dessas parcerias deva contemplar a análise junto a beneficiários. Considerando que essas organizações acessam recursos públicos, este estudo é justificado pelas suas implicações práticas para o campo da avaliação nessa perspectiva.

Além desta introdução, na seção seguinte é tratado, com base na literatura, sobre alguns exemplos de organizações da sociedade civil e seus objetivos, bem como sobre quais dimensões são comumente consideradas e como ocorre o processo de avaliação da utilidade social dessas organizações. Na terceira seção são apresentados os procedimentos metodológicos e na quarta seção os resultados e as análises, com base na percepção dos beneficiários das organizações estudadas. $\mathrm{Na}$ última, apresentaram-se as considerações finais, com sugestões para futuras pesquisas e apontando 0 longo caminho de pesquisa a ser percorrido após esse primeiro passo apresentado nesse artigo.

\section{REFERENCIAL TEÓRICO}

\subsection{Organizações da Sociedade Civil e seus objetivos}

França Filho (2004) diz que, apesar do conceito de terceiro setor e de economia solidária não serem sinônimos, ambos se referem a empreendimentos privados que teoricamente atuam no interesse público. Esses conceitos se diferem no contexto sociopolítico que surgem e na forma que se relacionam com o Estado e o mercado, mas ambos os tipos de organização voltam-se para "ajustes" do sistema no sentido de garantir o atendimento de necessidades sociais, sendo que as últimas ampliam suas preocupações às questões relacionadas com o desenvolvimento econômico, por meio de colaboração e democracia econômica.

Para fins deste estudo, admite-se como Organizações da Sociedade Civil aquelas consideradas no Marco Regulatório dessas organizações (Lei 13.019/2014), a saber: "entidade privada sem fins lucrativos", "sociedades cooperativas" em geral e "organizações religiosas que se dediquem a atividades ou a projetos de interesse público e de cunho social distintas das destinadas a fins exclusivamente religiosos". Cabe dizer que essas organizações da sociedade civil são as definidas como um conjunto de organizações que estão preocupadas com os problemas sociais e, diante deles, buscam influenciar 0 poder público e outros agentes para que ações sejam adotadas, inclusive com ou por elas próprias, no sentido de resolver esses problemas (FERES FARIA, 2010).

Dentre as organizações da social civil elencadas na tipologia de Feres Faria (2010), estão os empreendimentos de economia solidária. No rol dos vários tipos de empreendimentos de economia solidária, encontra-se um subconjunto chamado de finanças solidárias, que são experiências de economia solidária que estabelecem uma relação diferente com o dinheiro (FRANÇA FILHO, 2004), seja por meio do microcrédito, seja por meio do uso de moedas sociais. No Brasil, o exemplo mais marcante é o Banco Palmas, uma associação comunitária que mobilizou a criação de outras desse tipo no país (RIGO, 2014; RIGO; FRANÇA FILHO, 2017). Esses atuam no combate à exclusão financeira, mas principalmente no fomento ao desenvolvimento das economias locais (SANTANA, 2011). Segundo Toscano (2002), o Palmas é exemplo da capacidade de auto-organização da comunidade para formular políticas sociais ativas e democráticas e demonstra que a utilidade dessas organizações vai além da econômica.

Outro exemplo é o das empresas sociais, que se destacam por seu caráter de autogestão, com papéis difusos, que se propõem ser úteis à medida que objetivam fornecer serviços à coletividade, tendo 
como exemplos as cooperativas populares, além de fundações e associações sem fins lucrativos (FRANÇA FILHO, 2004). Benini e Benini (2010) argumentam que esses modelos resultam numa nova realidade cotidiana para os trabalhadores por serem eles os donos dos meios de produção e dos produtos gerados, e responsáveis pela organização e gestão dos empreendimentos. Nesse aspecto, Maurer (2016) afirma que organizações do tipo objetivam preencher a lacuna entre as demandas da sociedade por serviços e os recursos necessários para atendê-los.

Em geral, essas organizações buscam promover a socioeconomia, que se apresenta sob três perspectivas, dentre as quais a mais importante é a que resulta da junção de objetivos econômicos, sociais (educacionais, de saúde, ambientais...) e políticos para a promoção de uma agenda de desenvolvimento pautada em relações sociais humanizadas (LAVILLE, 2014). Elas têm em comum a pretensão de modificar o cenário em que atuam e, de forma abrangente, os seus objetivos voltam-se, por exemplo, para as dimensões sociais, culturais, políticos e econômicos (FRANÇA FILHO, 2004; KUYVEN, 2016; SILVA JR., 2016).

Quando essas organizações conseguem atingir tais objetivos, elas alcançam o que neste estudo se considera como utilidade social, como exposto adiante. Ademais, é salutar avaliar como esses resultados são alcançados, discutindo como deve ser essa avaliação e o que deve ser considerado, conforme também será tratado a seguir.

\subsection{Utilidade Social das Organizações da Sociedade Civil: 0 que é e como avaliar?}

Segundo Gadrey (2005), a utilidade social de uma organização está relacionada com a sua capacidade de gerar benefícios coletivos à sociedade, promovendo desenvolvimento equânime aonde está inserida. Esse processo envolve a dimensão econômica também, mas essa dimensão está subordinada a outras dimensões, tais como o fortalecimento de laços sociais, a emancipação política e a prevalência de espaços democráticos para a condução da vida social. Portanto, a utilidade social passa pela verificação de como os beneficiários a percebem, ou seja, de como para eles essas organizações impactam essas dimensões.

Contudo, embora Campos e Andion (2011) alertem sobre a importância da avaliação para essas organizações, o seu estudo demonstra que esse processo ainda é incipiente nas entidades estudadas pelos referidos autores. Mesmo nas organizações que promovem algum tipo de avaliação, os estudos mostram que os objetivos dessa e os modelos avaliativos que são utilizados não são claros. Nesse contexto, a primeira pergunta que se faz é sobre como essa avaliação deve ser feita. Sowa, Selden e Sandfort (2004) tratam sobre a dificuldade para encontrar uma forma válida para a avaliação da efetividade de organizações não governamentais. As autoras apresentam estudos que propõem alguns caminhos, mas entendem que não há um consenso na literatura, e argumentam que, embora haja debates sobre tema, é complicado definir quais são os fatores principais de impacto e se esses fatores são capazes de representar o todo. De todo modo, o estudo sobre o tema é justificado pela importância substancial dessas organizações.

Sowa, Selden e Sandfort (2004) propõem um modelo que considera duas dimensões: a gerencial e a dos programas, ambas divididas em duas subdimensões: capacidade e resultados. Alguns estudos consideram 0 alcance dos objetivos institucionais estabelecidos pela organização como medida de efetividade, outros consideram os indicadores de sustentabilidade econômica organizacional. As autoras mostram ainda que estudiosos analisam a efetividade das organizações por meio de fatores externos, baseados na relação entre a organização e o ambiente, tais como gestão dos recursos do ambiente, relação com atores-chave ou capacidade de satisfazer públicos-chave. Diante de tais variedades, argumentam que os estudos sobre o tema demonstram que a variação nas características das organizações demandará, por consequência, também a variação no modelo de avaliação. Mas, com 0 objetivo de definir um modelo geral que possa ser adotado, vários estudos tentam apresentar um modelo que contemple grande amplitude de fatores, tanto internos quanto externos (SOWA; SELDEN; SANDFORT, 2004). 
Apresentando uma proposta de Matriz para a avaliação da utilidade social de Bancos Comunitários de Desenvolvimento, Silva Jr. (2016) considera que esses bancos podem gerar resultados no que diz respeito a variáveis culturais, econômicas, políticas, socioambientais e institucionais, considerando para tal avaliação tanto variáveis qualitativas quanto quantitativas. Nessa mesma perspectiva, Santos (2016) argumenta que a mensuração do desempenho de uma organização pode ocorrer tanto por meio de dados monetários quanto não monetários. Na perspectiva não monetária, ele apresenta a Corporate Social Performance (CSP) como um meio para a avaliação do atendimento às demandas sociais. Em suma, a CSP buscar medir o quanto a organização atende às expectativas e aos anseios de seus stakeholders.

Já Mitchell e Berlan (2016) discutem elementos que influenciam o processo de avaliação, os estímulos, os obstáculos e o rigor metodológico envolvido. Nos obstáculos, eles apresentam a falta de tempo ou recursos financeiros, o medo de demonstrar as fragilidades, a falta de conhecimento especializado ou os desafios técnicos, entre eles, o de estabelecer variáveis adequadas e disponíveis para tal processo. Os estímulos cultura organizacional, exigências da gestão e probabilidade de demonstrar o sucesso da organização influenciam positivamente o rigor avaliativo; enquanto que 0 interesse pessoal o reduz. Quanto aos obstáculos, a falta de um financiador resulta numa relação positiva com o rigor avaliativo; enquanto os interesses inadequados, as dificuldades de medição e a baixa priorização provocam o inverso (MITCHEL; BERLAN, 2016).

Ainda em relação a como fazer a avaliação, Assumpção e Campos (2011) argumentam que há três momentos para a sua ocorrência: avaliação ex ante: tem o papel formativo e conceitual de estabelecer e identificar as necessidades e o planejamento para implantação do projeto; avaliação initineri: busca avaliar e monitorar o projeto em curso; e momento ex post: tem o papel somativo e avalia o projeto já realizado para estabelecer decisões de continuidade e alterações, bem como estabelecer 0 impacto da ação.

Nessa perspectiva, Fonseca, Oliveira e Rodrigues (2016) avaliam o mérito e o impacto de projetos de uma organização da sociedade civil, por meio de sete indicadores para avaliação do mérito e treze para os impactos, que resultaram em três instrumentos aplicados junto a colaboradores que atuam no projeto e seus beneficiários, esses que apontam que os projetos the proporcionam valorização pessoal e desenvolvimento educacional, cultural e social. É nessa perspectiva, considerando o momento ex post do impacto e a percepção dos beneficiários, que este estudo direciona sua atenção.

Assumpção e Campos (2011) ainda apresentam uma perspectiva de avaliação na qual as organizações são agrupadas como: históricas, novos movimentos, prestação de serviços, fundações e institutos e filantrópicas. Organizações apoiadas pela cooperação privada, pelo Estado ou por organismos internacionais tendem a utilizar modelos centrados em objetivos e na gestão, em função das necessidades de estabelecer indicadores sólidos de eficácia da intervenção social. Já as organizações que atuam apoiadas por grupos populares consistentes tendem a utilizar modelos centrados na participação, atribuindo valores intuicionistas e pluralistas com papel formativo, por meio de discussões acerca das ações, que geram dados que possibilitam o julgamento da intervenção.

Em outra perspectiva de avaliação, Benini e Benini (2015) apresentam uma discussão sobre 0 alcance das ações organizacionais, dividindo-as em dois estágios. No primeiro, as ações resultam em submissão à lógica mercantil, em que recursos públicos previstos em lei são acessados, ou ainda são constituídas por políticas públicas de maior complexidade, por exemplo, incluindo formação, crédito e inclusão produtiva, ou ainda, pela sustentação estatal da viabilidade econômica desses empreendimentos. No segundo estágio, com maior possibilidade de contra-hegemonia, estão iniciativas que buscam a sustentação de novas relações sociais, em que os recursos públicos previstos em lei são destinados à recuperação dos meios de produção, que resulte na substituição do sistema tradicional por um sistema pautado na lógica da economia solidária. Considerando essa classificação, a avaliação dessas organizações poderia analisar, por exemplo, em qual dos estágios suas ações estariam, se em conformação ou em confrontação com o sistema. 
Feita essa discussão, com estudos que apresentam indícios sobre o processo de avaliação, trata-se a partir daqui sobre dimensões e variáveis que podem ser consideradas na avaliação da utilidade social em organizações de economia solidária Por exemplo, e num contexto mais amplo, Kuyven (2016) aponta que, numa organização social, a renda obtida numa jornada tradicional de trabalho equivale ao dobro do salário mínimo, o que indica que essas organizações contribuem para o aumento da renda, uma variável relacionada com a dimensão econômica. Esse fato contribui para a diminuição da exploração do trabalho.

Kuyven (2016) aponta ainda que, embora nas organizações analisadas haja discrepâncias na distribuição de renda entre estratos da sociedade, quando se compara a renda de um desses estratos, por exemplo, mulheres vinculadas a essas organizações com outras que trabalham no mercado tradicional, percebe-se que é justamente nesse estrato que o nível de renda mais aumenta. No longo prazo, portanto, a chance de um equilíbrio na distribuição de renda é maior em tais organizações. Nesse contexto, Laville (2014) afirma que nesse tipo de economia novas relações de trabalho poderão ser estabelecidas, nas quais imperam o diálogo na tentativa de discutir e aprovar regras que não permitam a existência de condições precárias, em que as proteções ao direito ao trabalho comunguem com a coesão social e resultem em novas configurações de organização. Assim, Kuyven (2016) aponta que, para avaliar as condições de vida, a geração e o equilíbrio na distribuição de renda (dimensões econômicas) e a qualidade do trabalho (dimensão social) são variáveis que devem ser consideradas.

França Filho (2004) considera que essas iniciativas colocam os objetivos sociais, culturais e políticos como prioritários, subordinando interesses econômicos a essas prioridades como um meio para que esses objetivos sejam alcançados. Os empreendimentos possibilitam às pessoas "continuarem vinculadas ao seu modo tradicional de vida, garantindo os seus direitos territoriais, socioeconômicos, ambientais e culturais, respeitando e valorizando suas identidades e instituições" (KUYVEN, 2016, p. 107). Desses argumentos, é possível extrair mais algumas dimensões, a saber: social, cultural e política; e, como argumenta Kuyven (2016), também os aspectos territoriais e ambientais.

Outro aspecto relacionado à avaliação dessas organizações é a capacidade de articulação com entidades públicas e privadas. Para Guimarães (2012), esse é um dos elementos que contribui para a sua perenidade. A autora argumenta como os empreendimentos de Matarandiba, locus do seu estudo empírico, dialogam com instituições públicas e sociedades empresárias. Essa, portanto, é a variável de articulação institucional, vinculada à dimensão tecnológica, levada para o instrumento utilizado neste estudo.

Estudando o Banco Comunitário de Matarandiba, Santana (2011) verificou que todas as famílias da comunidade já haviam sido beneficiadas com algum crédito no banco, tanto quem não precisaria quanto aqueles que dependem dele para uma vida mais digna. Contudo, alerta que é preciso avançar em outros serviços financeiros para que se tenha, de fato, uma inclusão financeira, o que contribuiria inclusive para a sustentabilidade do próprio banco. Esse argumento diz respeito à variável de acesso a serviços de dimensão social.

Afirma Santana (2011) ainda que o banco gerava resultados para além do econômico ou social, contribuindo também para dimensão política, com a representação indireta frente a outros atores. Noutro aspecto, quanto às precárias condições de lazer na comunidade, houve uma revalorização das manifestações da cultura local em decorrência do trabalho realizado por uma das associações locais (SANTANA, 2011), aspectos que dizem respeito à dimensão cultural.

Santana (2011) ainda demonstra a influência na mobilização do poder público para atender as demandas locais e a contribuição para a articulação e a inserção política com outras redes e empreendimentos para além da comunidade. Além disso, afirma que há o desenvolvimento do sentimento de pertencimento e, com a ação da rede de empreendimentos, o fortalecimento das relações associativas e o surgimento de novas lideranças no território. É possível extrair variáveis relacionadas com a dimensão tecnológica (articulação com pares) e a política (emancipação e representação direta). Nesse aspecto emancipatório, concordam Benini e Benini (2015) e Caruana e Srnec (2013). 
Nesse contexto, em relação a quais dimensões considerar no processo de avaliação, França Filho (2004) afirma que essas organizações objetivam impactar tanto o nível da renda quanto as condições de vida em geral, de reivindicação por direitos sociais, tais como cultura, política e serviços. Santos (2006) corrobora esse argumento, mas relata que não são encontrados indicadores para mensurar 0 atendimento dessa demanda.

Como visto, os processos avaliativos acerca da utilidade social dessas organizações envolvem considerável complexidade e existe consenso dentre os estudos aqui apontados de que é necessário considerar várias dimensões dos resultados alcançadas por essas organizações. Percebe-se ainda que essas dimensões podem ser definidas e subdivididas de diferentes formas e com base em diferentes perspectivas e critérios. Nesse artigo e primeiro exercíocio de compreensão da utilidade social de empreendimentos de economia solidária, basear-se-á em seis dimensões, quais sejam: cultural, econômica, política, tecnológica, ambiental e social. Essas dimensões e as possíveis variáveis que podem ser utilizadas para entendê-las estão sintetizadas no Quadro 01.

Quadro 01 - Proposta de dimensões e suas variáveis para a avaliação da Utilidade Social

\begin{tabular}{|c|c|c|c|}
\hline CONCEITO & DIMENSÕES & AUTORES & VARIÁVEIS ESPERADAS \\
\hline \multirow{20}{*}{ 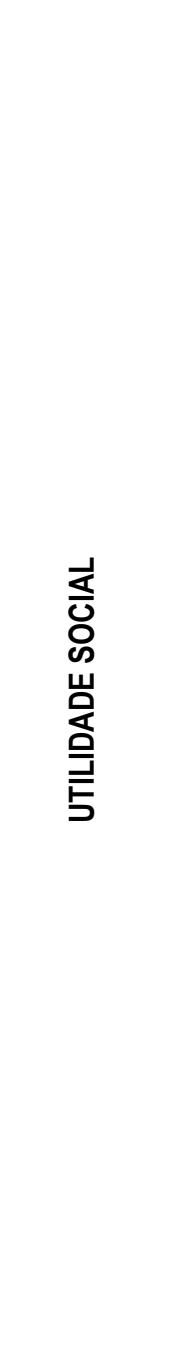 } & \multirow{3}{*}{ Cultural } & \multirow{3}{*}{$\begin{array}{l}\text { Assumpção, Campos (2011); Benini, Benini (2015); } \\
\text { Caruana, Srnec (2013); França Filho (2004); Guimarães } \\
\text { (2012); Santana (2011), Silva Júnior (2016). }\end{array}$} & Lazer \\
\hline & & & Esporte \\
\hline & & & Manifestações culturais \\
\hline & \multirow{4}{*}{ Econômica } & \multirow{4}{*}{$\begin{array}{c}\text { Assumpção, Campos (2011); Benini, Benini (2015); } \\
\text { Caruana, Srnec (2013); França Filho (2004); Guimarães } \\
\text { (2012); Kuyven (2016); Laville (2014); Santana (2011); } \\
\text { Santos (2016); Sowa, Selden, Sandfort (2004), Silva } \\
\text { Júnior (2016). }\end{array}$} & Renda \\
\hline & & & Emprego \\
\hline & & & Consumo \\
\hline & & & Igualdade econômica \\
\hline & \multirow{3}{*}{ Política } & \multirow{3}{*}{$\begin{array}{l}\text { Assumpção, Campos (2011); Benini, Benini (2015); } \\
\text { Caruana, Srnec (2013); França Filho (2004); Guimarães } \\
\text { (2012); Santana (2011), Silva Júnior (2016). }\end{array}$} & Representação direta \\
\hline & & & Participação eleitoral \\
\hline & & & Representação indireta \\
\hline & \multirow{3}{*}{ Tecnológica } & \multirow{3}{*}{$\begin{array}{l}\text { Guimarães (2012); Sowa, Selden, Sandfort (2004); Silva } \\
\text { Júnior (2016). }\end{array}$} & Inovação social \\
\hline & & & Articulação institucional \\
\hline & & & Recursos tecnológicos \\
\hline & \multirow{3}{*}{ Ambiental } & \multirow{3}{*}{$\begin{array}{l}\text { França Filho (2004); Guimarães (2012); Santana (2011); } \\
\text { Silva Júnior (2016). }\end{array}$} & Projetos ambientais \\
\hline & & & Cursos de capacitação \\
\hline & & & Consciência Ambiental \\
\hline & \multirow{4}{*}{ Social } & \multirow{4}{*}{$\begin{array}{c}\text { Assumpção, Campos (2011); Benini, Benini (2015); } \\
\text { Caruana, Srnec (2013); França Filho (2004); Guimarães } \\
\text { (2012); Kuyven (2016); Laville (2014); Santana (2011); } \\
\text { Santos (2016); Sowa, Selden, Sandfort (2004), Silva } \\
\text { Júnior (2016). }\end{array}$} & Acesso a serviços \\
\hline & & & Pertencimento \\
\hline & & & Educação \\
\hline & & & Qualidade do emprego \\
\hline
\end{tabular}

Fonte: Elaboração própria com base no levantamento da literatura (2017).

A partir do corpo teórico aqui apresentado, percebe-se que o processo de avaliação da utilidade social dessas organizações é tema complexo, que envolve múltiplas dimensões e variáveis, demonstradas anteriormente. É importante para o desenvolvimento de metodologias adequadas para 
essa avaliação explorar se essas dimensões e variáveis afetam mesmo os beneficiários. Neste estudo, buscaram-se os primeiros indícios de uma metodologia de avaliação da utilidade social desse tipo de organização comunitária, conforme apresentado.

\section{PROCEDIMENTOS METODOLÓGICOS}

A presente pesquisa, com abordagem principalmente qualitativa, identificou as dimensões da utilidade social de organizações da sociedade civil apresentadas na literatura e as confrontou com a percepção de beneficiários de organizações da sociedade civil localizadas na llha de Matarandiba em Vera Cruz-BA. Esta pesquisa é também exploratória, quando ainda há pouco conhecimento acumulado e sistematizado sobre o tema (VERGARA, 2010), na forma como aqui estudado, já que se analisaram as dimensões de utilidade social na perspectiva de beneficiários, aspecto que não tem sido considerado nas avaliações dessas organizações, mas que é considerado nos estudos de Fonseca, Oliveira e Rodrigues (2016); Guimarães (2012); Kuyven (2016); Santana (2011) e Silva Jr. (2016).

Matarandiba é uma dentre as milhares de comunidades brasileiras em que as dificuldades decorrentes da desigualdade econômica e social não são surpresa. Nesse sentido, Rigo, França Filho e Leal (2015, p. 22) afirmam que ela "acumula um conjunto de déficits no plano educacional, econômico, ambiental, político e social, que a torna um desses territórios claramente marcados pela presença de índices relativamente significativos de pobreza". Nesse cenário, há uma rede de empreendimentos solidários, que iniciou suas atividades em 2007, em parceria com uma multinacional que atua na localidade e instituições de apoio e fomento à economia solidária, como uma incubadora universitária. As parcerias resultaram em uma rede de organizações locais que atua em prol do desenvolvimento do território em diferentes aspectos e por meio de diferentes projetos. Sendo assim, a Associação Sociocultural de Matarandiba (ASCOMAT) e a Associação Comunitária de Matarandiba (ASCOMA) viabilizam projetos, como: o Banco Comunitário llhamar; o Vivetur, que trabalha com o turismo de base comunitária; o centro de informática Informar; a rádio e a padaria comunitária; e o Fórum de Desenvolvimento Comunitário de Matarandiba. Essa rede busca "aumentar o grau de conhecimento, participação e implicação das pessoas em torno dos problemas comuns afetando a vida de todos em seu local" (PROJETO ECOSMAR, 2017).

Nessa pesquisa, utilizou-se um questionário estruturado e fechado (VERGARA, 2010), contemplando as dimensões e as variáveis apontadas pela literatura. Os itens que compuseram tal instrumento foram construídos a partir do referencial deste estudo, e nele os respondentes apontavam seu grau de concordância com 0 item, considerando uma escala de intensidade, com as seguintes opções: 1 (Discordo Totalmente), 2 (Discordo), 3 (Concordo), 4 (Concordo Totalmente), para que os respondentes se manifestassem sobre o nível de concordância com as afirmações, e ainda as opções 5 (Não sei responder), quando havia desconhecimento sobre a variável avaliada e 6 (Não se aplica), quando não vivera o contexto descrito na afirmação.

As questões envolvendo as seis dimensões de utilidade social contêm cinco proposições para cada uma delas, totalizando trinta itens, distribuídos no instrumento na seguinte sequência: Cultural (1; $7 ; 13 ; 19$ e 25), Econômica (2; 8; 14; 20 e 26), Política ( $3 ; 9 ; 15 ; 21$ e 27), Técnica (4; 10; 16; 22 e 28), Ambiental $(5 ; 11 ; 17 ; 23$ e 29) e Social $(6 ; 12 ; 18 ; 24$ e 30). Como não foi encontrado questionário validado, com as características pretendidas por esse este estudo, foi preciso recorrer a um processo de validação, mediante pré-teste com a avaliação de dois professores doutores, ambos com domínio sobre a área e sobre os procedimentos metodológicos concernentes à construção desse tipo de instrumento.

A coleta foi realizada em março e abril de 2017 por meio de visitas de campo e aos domicílios existentes na llha de Matarandiba, considerando que cada um deles representa um núcleo de potenciais beneficiários. Para a definição da amostra, foi preciso buscar inicialmente o número de domicílios existentes. O Sistema de Informação de Atenção Básica (SIAB), conforme informação da Secretaria Municipal de Saúde de Vera Cruz, de março de 2015, apresenta dados referentes a 119 domicílios. 
Contudo, segundo essa Secretaria, esse número corresponde a, aproximadamente, $50 \%$ do total. Portanto, estima-se que a população total deste estudo corresponda a aproximadamente 238 domicílios.

Estimando um tempo médio de 12 minutos para aplicação de cada questionário, considerando os dias de visita e dois pesquisadores aplicando, objetivou-se atingir um mínimo de 150 domicílios. A escolha desses domicílios se deu por sorteio aleatório por meio do software Microsoft Excel ${ }^{\circledR}$, tendo a aplicação começada a partir do segundo domicílio à direita da rua estabelecida como ponto de partida. A partir desse, foram visitados os domicílios seguintes a cada intervalo de dois, alternando-se entre 0 lado direito e o esquerdo da via. Quando por algum motivo não foi encontrado morador no domicílio sorteado, recorreu-se ao imediatamente anterior ou, na sequência, ao posterior. Cada questionário recebeu uma numeração que serviu de guia no momento da coleta. Os dados foram, então, tabulados na sequência em que foram coletados. Em função de o tempo demandado para aplicação do questionário ter sido maior do que o estimado, além de muitos domicílios estarem fechados, foi aplicado o questionário junto a 31 domicilios (13\% da população).

Foram realizadas análises descritivas para sexo, idade, nível de escolaridade, ocupação e tempo de residência na comunidade dos respondentes. Além disso, por meio também de análise descritiva, foi verificado o nível de concordância dos respondentes quanto ao impacto das ações das organizações, considerando também medidas de tendência central e medidas de dispersão, com base em Fávero et al. (2009) e Field (2009).

Cumpre apresentar algumas ressalvas aplicáveis às análises das tabelas apresentadas na seção seguinte para todas as dimensões. Primeiro, a concordância dos respondentes está demonstrada em percentuais nas colunas DT (discordo totalmente), D (discordo), C (concordo) e CT (concordo totalmente). Há, ainda, como constou no questionário, os percentuais quanto às opções NSR (Não sei responder) e NSA (Não se aplica). A soma desses percentuais representa o total dos respondentes de cada variável. Quando o percentual de concordância (Concordo + Concordo Totalmente) prevalecer, a análise é feita pela soma dos percentuais de ambas as opções, o mesmo para discordâncias. Porém, nas análises de tendência central e dispersão, foram excluídas as respostas do tipo NSR e NSA, pois a pretensão era saber o quanto concordam/discordam sobre o impacto das ações. Assim, os dados sobre Média, Erro, Desvio-Padrão, Coeficiente de Variação (CV) e Nível de Confiança são apenas em função dos respondentes $(n)$ que se manifestaram quanto às opções $D T, D, C$ e CT.

Foi feita ainda uma análise no que diz respeito à possibilidade de extrapolar os resultados deste estudo para a população. Nesse aspecto, analisou-se o Erro, o Desvio- Padrão e o Nível de Confiança, todos com valores baixos, o que indicaria que, com 95\% de confiança, é possível admitir que os resultados obtidos neste estudo amostral representem adequadamente a realidade da população (FIELD, 2009). A análise do Coeficiente de Variação (CV) reforçaria esse entendimento. Em todas as tabelas, algumas questões apresentam CV superiores a 30\%, que Fávero et al. (2009) consideram o máximo a ser aceito. De todo modo, admite-se que os achados correspondem ao contexto analisado da comunidade de Matarandiba. Com isso, foram identificadas as dimensões confirmadas pelos beneficiários, conforme relato a seguir.

\section{ANÁLISES E RESULTADOS}

A amostra é formada em sua grande maioria por representantes do sexo feminino (87\%), que no total tem idade média de 47 anos. Quanto ao tempo de residência, nove respondentes residiam a menos de 10 anos. Os demais respondentes apresentaram um tempo médio de residência de 37 anos, o que demonstra que conhecem bem a comunidade. Quanto ao nível de formação, uma respondente era não alfabetizada, $61 \%$ possuíam ensino médio e $29 \%$ ensino fundamental. Apenas $6 \%$ possuíam graduação. No que diz respeito à ocupação, $32 \%$ trabalham em casa, $26 \%$ são aposentados(as), $10 \%$ trabalham em empresa privada, mesmo percentual dos que informaram desenvolver trabalho informal, e $6 \%$ trabalham em pública, mesmo número dos que trabalham com pesca e dos que não trabalham. Outra respondente afirmou que atua em uma organização da sociedade civil. 
Feita essa caracterização, apresenta-se a seguir as análises sobre a utilidade social.

\section{1. "Utilidade Social" das organizações sociais na percepção dos beneficiários}

Neste trabalho, a utilidade social das organizações é avaliada a partir da capacidade delas implicarem seis dimensões da vida humana: cultural, econômica, política, tecnológica, ambiental e social. Assim sendo, é apresentada a seguir a percepção de potenciais beneficiários da llha de Matarandiba sobre o impacto das ações de organizações existentes naquela comunidade. Para tal análise, das 31 respostas obtidas, foram excluídas as respostas dos que possuíam menos de cinco anos de residência na comunidade, sendo a análise correspondente ao " $\mathrm{n}$ " apresentado em cada uma das variáveis. Iniciamse as análises a partir da Tabela 1 sobre a dimensão cultural:

Tabela 1 - Utilidade Social quanto à dimensão Cultural

\begin{tabular}{|l|c|c|c|c|c|c|c|c|c|c|c|c|c|}
\hline \multicolumn{1}{|c|}{ Questão } & DT & D & C & CT & NSR & NSA & Total & $\begin{array}{c}\text { Médi } \\
\text { a }\end{array}$ & $\begin{array}{c}\text { Erro } \\
\text { Desv } \\
\text { io }\end{array}$ & CV & n & $\begin{array}{c}\text { Confiança } \\
\text { (95\%) }\end{array}$ \\
\hline $\begin{array}{l}\text { A partir do surgimento das associações, cu tive } \\
\text { mais acesso a livros e filmes. }\end{array}$ & $4 \%$ & $31 \%$ & $46 \%$ & $4 \%$ & $0 \%$ & $15 \%$ & $100 \%$ & 3 & 0,14 & 0,65 & $24 \%$ & 22 & 0,29 \\
\hline $\begin{array}{l}\text { Após surgimento das associações, passei a } \\
\text { participar das atraçoses culturais da ilha (Samba de } \\
\text { Roda, Boi Estrela, Zé de Vale...). }\end{array}$ & $0 \%$ & $27 \%$ & $23 \%$ & $31 \%$ & $0 \%$ & $19 \%$ & $100 \%$ & 3 & 0,18 & 0,80 & $2 \% \%$ & 21 & 0,37 \\
\hline $\begin{array}{l}\text { Filhos e/ou sobrinhos meus participam do projeto } \\
\text { de leitura da Ascomat. }\end{array}$ & $8 \%$ & $12 \%$ & $36 \%$ & $8 \%$ & $12 \%$ & $24 \%$ & $100 \%$ & 3 & 0,22 & 0,87 & $32 \%$ & 16 & 0,47 \\
\hline $\begin{array}{l}\text { A partir do surgimento das as acociações, cu comecei } \\
\text { a desenvolver uma atividade esportiva. }\end{array}$ & $17 \%$ & $43 \%$ & $13 \%$ & $0 \%$ & $0 \%$ & $26 \%$ & $100 \%$ & 2 & 0,16 & 0,69 & $34 \%$ & 18 & 0,34 \\
\hline $\begin{array}{l}\text { As organizações da Rede Ecosmar possibilitou que } \\
\text { tivéssemos melhores espaços para atividades de } \\
\text { lazer. }\end{array}$ & $4 \%$ & $24 \%$ & $60 \%$ & $4 \%$ & $0 \%$ & $8 \%$ & $100 \%$ & 3 & 0,13 & 0,62 & $23 \%$ & 24 & 0,26 \\
\hline
\end{tabular}

Fonte: Elaboração própria com base nos dados da pesquisa (2017).

No que diz respeito a essa dimensão, percebe-se que os respondentes acreditam que as organizações contribuem para que eles tenham acesso a livros e filmes (50\% de concordância), para a participação em atrações culturais e em projeto de leitura promovido por uma das associações (com, respectivamente, $54 \%$ e $44 \%$ de concordância). Quanto ao acesso a melhores espaços de lazer, $64 \%$ concordam que os projetos da rede Ecosmar contribuíram para melhoria das condições dos espaços para tal. Nesse sentido, estes achados confirmam que esse tipo de organização é útil para 0 desenvolvimento cultural dos cidadãos, como afirmam Assumpção e Campos (2011); Benini e Benini (2015); Caruana e Srnec (2013), França Filho (2004), Guimarães (2012), Santana (2011) e Silva Júnior (2016).

Porém, há uma variável relacionada com a prática de esporte sobre a qual a maioria $(60 \%)$ dos respondentes discordou que as associações influenciaram. Tal resultado pode ser, justamente, em função de $23 \%$ de a população ter mais do que 50 anos e a realização de algum tipo de atividade física para pessoas da terceira idade não ter sido estimulada na comunidade. Pode ser, ainda, que outros aspectos como a indisponibilidade de tempo e a falta de praças esportivas impeçam a realização desse tipo de atividade por meio das organizações sociais locais.

Quanto à dimensão econômica, a Tabela 2 apresenta os resultados sobre a percepção dos respondentes, considerando as ressalvas já feitas no início da seção. 
Tabela 2 - Utilidade Social quanto à dimensão Econômica

\begin{tabular}{|l|c|c|c|c|c|c|c|c|c|c|c|c|c|}
\hline \multicolumn{1}{|c|}{ Questão } & DT & D & C & CT & NSR & NSA & Total & $\begin{array}{c}\text { Médi } \\
\text { a }\end{array}$ & Erro & $\begin{array}{c}\text { Desv } \\
\text { io }\end{array}$ & CV & $\begin{array}{c}\text { Confiança } \\
\text { (95\%) }\end{array}$ \\
\hline $\begin{array}{l}\text { A partir do surgimento das associações, minha } \\
\text { renda e/ou da minha família aumentou. }\end{array}$ & $8 \%$ & $44 \%$ & $24 \%$ & $0 \%$ & $0 \%$ & $24 \%$ & $100 \%$ & 2 & 0,15 & 0,62 & $29 \%$ & 18 & 0,31 \\
\hline $\begin{array}{l}\text { Em sua opinião Banco Ilhamar possibilita a } \\
\text { solidariedade e cooperação entre os empresários, } \\
\text { moradores e os agentes de créditos financeiros. }\end{array}$ & $0 \%$ & $12 \%$ & $65 \%$ & $8 \%$ & $12 \%$ & $4 \%$ & $100 \%$ & 3 & 0,10 & 0,49 & $16 \%$ & 22 & 0,22 \\
\hline $\begin{array}{l}\text { O trabalho realizado pelas associações locais } \\
\text { contribuição para a redução da pobreza na ilha. }\end{array}$ & $0 \%$ & $12 \%$ & $52 \%$ & $16 \%$ & $20 \%$ & $0 \%$ & $100 \%$ & 3 & 0,14 & 0,62 & $20 \%$ & 19 & 0,30 \\
\hline $\begin{array}{l}\text { O trabalho realizado pelas associações locais, } \\
\text { permite uma distribuição mais igualitária da renda } \\
\text { entre todos da comunidade. }\end{array}$ & $15 \%$ & $46 \%$ & $23 \%$ & $0 \%$ & $15 \%$ & $0 \%$ & $100 \%$ & 2 & 0,15 & 0,71 & $33 \%$ & 22 & 0,31 \\
\hline $\begin{array}{l}\text { A partir do surgimento das as ociações, cu passci a } \\
\text { comprar mais na própria ilha. }\end{array}$ & $8 \%$ & $31 \%$ & $42 \%$ & $12 \%$ & $0 \%$ & $8 \%$ & $100 \%$ & 3 & 0,16 & 0,78 & $30 \%$ & 24 & 0,33 \\
\hline
\end{tabular}

Fonte: Elaboração própria com base nos dados da pesquisa (2017).

Verificou-se que $73 \%$ dos respondentes consideram que o banco comunitário contribui para a articulação entre empresários, moradores e agentes de créditos, o que contribui para o desenvolvimento e a geração de emprego, conforme captado nas respostas dadas. Ainda nessa direção, concordam que as associações locais contribuem para o estímulo do consumo local (54\%). Esses resultados coadunam com os achados de Assumpção e Campos (2011); Benini e Benini (2015); Caruana e Srnec (2013), França Filho (2004), Guimarães (2012), Kuyven (2016), Laville (2014), Santana (2011), Santos (2016), Sowa, Selden, Sandfort (2004) e Silva Júnior (2016).

Por outro lado, não foi confirmada a contribuição das ações das organizações na promoção de distribuição adequada da renda (61\% de discordância). Ademais, embora a maioria tenha concordado no que diz respeito à redução da pobreza na ilha (68\%), há discordância quanto à contribuição para 0 aumento de sua renda e/ou da família ( $52 \%$ de discordância). Tal aparente contradição poderia ser explicada ao se considerar que há uma sensação geral de que as organizações contribuem para a economia local, porém sem necessariamente afetá-las diretamente. Assim sendo, observa-se que não há uma percepção de impacto direto no que diz respeito ao aumento da renda, o que indica que naquela comunidade ainda é circunscrito o impacto sobre essa variável.

A literatura também aponta que essas organizações podem alcançar outros objetivos, por exemplo, na dimensão política, conforme os resultados na Tabela 3.

Tabela 3 - Utilidade Social quanto à dimensão Política

\begin{tabular}{|l|c|c|c|c|c|c|c|c|c|c|c|c|c|}
\hline \multicolumn{1}{|c|}{ Questão } & DT & D & C & CT & NSR & NSA & Total & $\begin{array}{c}\text { Médi } \\
\text { a }\end{array}$ & Erro & $\begin{array}{c}\text { Desv } \\
\text { io }\end{array}$ & CV & n & $\begin{array}{c}\text { Confiança } \\
\text { (95\%) }\end{array}$ \\
\hline $\begin{array}{l}\text { Depois que a Ascoma passou a cxistir, a } \\
\text { comunidade é mais respeitada pela Dow. }\end{array}$ & $4 \%$ & $8 \%$ & $50 \%$ & $12 \%$ & $19 \%$ & $8 \%$ & $100 \%$ & 3 & 0,16 & 0,71 & $24 \%$ & 19 & 0,34 \\
\hline $\begin{array}{l}\text { Atualmente, em função do trabalho da Ascoma, os } \\
\text { vereadores c a prefeitura dão mais atenção à } \\
\text { comunidade local. }\end{array}$ & $16 \%$ & $24 \%$ & $44 \%$ & $0 \%$ & $16 \%$ & $0 \%$ & $100 \%$ & 2 & 0,17 & 0,78 & $34 \%$ & 22 & 0,35 \\
\hline $\begin{array}{l}\text { As associąões locais contribuíram para que } \\
\text { tivés semos candidatos a vereador da llha na última } \\
\text { eleição. }\end{array}$ & $0 \%$ & $44 \%$ & $32 \%$ & $0 \%$ & $16 \%$ & $8 \%$ & $100 \%$ & 2 & 0,11 & 0,50 & $21 \%$ & 20 & 0,24 \\
\hline $\begin{array}{l}\text { O debatc com os vereadores, organizado pela } \\
\text { Ascoma, aumentou a minha consciência política c } \\
\text { ajudou na decisão do meu voto. }\end{array}$ & $4 \%$ & $8 \%$ & $27 \%$ & $15 \%$ & $8 \%$ & $38 \%$ & $100 \%$ & 3 & 0,26 & 0,90 & $31 \%$ & 12 & 0,57 \\
\hline $\begin{array}{l}\text { Os empreendimentos da Rede Ecosmar funcionam } \\
\text { por meio de uma gestão democrática cu me sinto à } \\
\text { vontade para participar. }\end{array}$ & $8 \%$ & $8 \%$ & $50 \%$ & $0 \%$ & $8 \%$ & $27 \%$ & $100 \%$ & 3 & 0,17 & 0,70 & $2 r \%$ & 17 & 0,36 \\
\hline
\end{tabular}

Fonte: Elaboração própria com base nos dados da pesquisa (2017).

Nesse aspecto, foi verificado que os respondentes concordam que a atuação das organizações da Rede Ecosmar contribuiu para que a empresa multinacional instalada na comunidade passasse a 
respeitar mais a comunidade $(62 \%)$ e, considerando que é premissa dessas organizações a atuação democrática e aberta aos membros da comunidade em que estão inseridas ( $50 \%$ confirmam que elas agem assim), as organizações lhes servem como meio de representação indireta. Ainda no que diz respeito à representação indireta, a questão que tratava sobre a atenção dada à comunidade por parte de vereadores e da prefeitura em função da influência da Ascoma restou inconclusiva, já que $40 \%$ discordaram e $44 \%$ concordaram.

De todo modo, a análise conjunta com a variável sobre a atuação democrática e sobre a influência exercida sobre a multinacional permitiu confirmar que tais organizações exercem a representação indireta na percepção dos respondentes. Os moradores apontaram também a contribuição para o aumento da consciência política e na decisão do voto $(42 \%)$, o que ao nosso ver fortalece a participação dos moradores no processo eleitoral. Esses resultados confirmam o que argumentam Assumpção e Campos (2011); Benini e Benini (2015); Caruana e Srnec (2013), França Filho (2004), Guimarães (2012), Santana (2011) e Silva Júnior (2016). Contudo, quanto à capacidade de impactar na representação direta, os respondentes em sua maioria discordam (44\%) que essas organizações cumpram tal papel.

$\mathrm{Na}$ dimensão tecnológica, houve concordância para todas as proposições apresentadas, conforme evidenciado na Tabela 4.

Tabela 4 - Utilidade Social quanto à dimensão Tecnológica

\begin{tabular}{|l|c|c|c|c|c|c|c|c|c|c|c|c|c|}
\hline \multicolumn{1}{|c|}{ Questão } & DT & D & C & CT & NSR & NSA & Total & $\begin{array}{c}\text { Médi } \\
\text { a }\end{array}$ & Erro & $\begin{array}{c}\text { Desv } \\
\text { io }\end{array}$ & CV & n & $\begin{array}{c}\text { Confiança } \\
\text { (95\%) }\end{array}$ \\
\hline $\begin{array}{l}\text { As associações locais permitiram a interação da } \\
\text { nossa comunidade com outras comunidades c } \\
\text { redes, nos fortalecendo. }\end{array}$ & $0 \%$ & $19 \%$ & $31 \%$ & $12 \%$ & $38 \%$ & $0 \%$ & $100 \%$ & 3 & 0,17 & 0,68 & $23 \%$ & 16 & 0,36 \\
\hline $\begin{array}{l}\text { As associações vinculadas ao Projeto Ecosmar } \\
\text { mostram-se mais cficicntes c confiáveis dos que o } \\
\text { Clube das Mães, a Sobema e o Conselho } \\
\text { Comunitário. }\end{array}$ & $0 \%$ & $8 \%$ & $35 \%$ & $23 \%$ & $27 \%$ & $8 \%$ & $100 \%$ & 3 & 0,15 & 0,64 & $20 \%$ & 17 & 0,33 \\
\hline $\begin{array}{l}\text { Entendo que poucas comunidades possuem uma } \\
\text { tecnologia de turismo de base comunitária como a } \\
\text { que temos aqui. }\end{array}$ & $4 \%$ & $12 \%$ & $50 \%$ & $15 \%$ & $19 \%$ & $0 \%$ & $100 \%$ & 3 & 0,16 & 0,73 & $24 \%$ & 20 & 0,34 \\
\hline $\begin{array}{l}\text { A forma como os empreendimentos solidários da } \\
\text { nossa comunidade está organizada permite que csse } \\
\text { modelo de empreendimento possa ser replicado por } \\
\text { outras comunidades de nossa região. }\end{array}$ & $4 \%$ & $4 \%$ & $69 \%$ & $19 \%$ & $4 \%$ & $0 \%$ & $100 \%$ & 3 & 0,13 & 0,64 & $21 \%$ & 25 & 0,26 \\
\hline $\begin{array}{l}\text { Os empreendimentos da Rede Ecosmar contribuíram } \\
\text { para que cu e minha família passássemos a ter } \\
\text { acesso a computadores e internet. }\end{array}$ & $4 \%$ & $8 \%$ & $56 \%$ & $16 \%$ & $0 \%$ & $16 \%$ & $100 \%$ & 3 & 0,16 & 0,73 & $24 \%$ & 20 & 0,34 \\
\hline
\end{tabular}

Fonte: Elaboração própria com base nos dados da pesquisa (2017).

Em relação à atuação em rede com outras comunidades, apontando para a possibilidade de fortalecimento da ilha, $44 \%$ concordam que as associações locais permitem tal atuação (contra 19\% dos que discordam). Também concordam quanto à apresentação dos empreendimentos como exemplos de uma tecnologia social mais eficiente e confiável (58\%) e replicável para outros contextos (88\%). Em relação ao aspecto da inovação social, $65 \%$ concordam com tal utilidade social dessas organizações, da mesma forma que concordam (72\%) que elas também contribuem para que eles passassem a ter acesso a recursos tecnológicos, confirmando o que afirmam Guimarães (2012), Sowa, Selden, Sandfort (2004) e Silva Júnior (2016).

A quinta dimensão aqui considerada é a ambiental. Nesse aspecto, analisa-se tanto a percepção dos respondentes quanto a contribuição das organizações na conscientização dos indivíduos, além da realização de projetos ambientais e cursos de capacitação correlatos, conforme Tabela 5. 
Tabela 5 - Utilidade Social quanto à dimensão Ambiental

\begin{tabular}{|l|c|c|c|c|c|c|c|c|c|c|c|c|c|}
\hline Questão & DT & D & C & CT & NSR & NSA & Total & $\begin{array}{c}\text { Médi } \\
\text { a }\end{array}$ & Erro & $\begin{array}{c}\text { Desv } \\
\text { io }\end{array}$ & CV & n & $\begin{array}{c}\text { Confiança } \\
\text { (95\%) }\end{array}$ \\
\hline $\begin{array}{l}\text { Com o trabalho desenvolvido pela Rede Ecosmar, } \\
\text { tenho mais consciência das questões ambientais. }\end{array}$ & $0 \%$ & $12 \%$ & $60 \%$ & $8 \%$ & $12 \%$ & $8 \%$ & $100 \%$ & 3 & 0,11 & 0,51 & $17 \%$ & 20 & 0,24 \\
\hline $\begin{array}{l}\text { A Rede Ecosmar foi responsável por conscientizar } \\
\text { mais os moradores da comunidade sobre a } \\
\text { importância do respeito ao periodo do "defeso". }\end{array}$ & $8 \%$ & $31 \%$ & $38 \%$ & $4 \%$ & $19 \%$ & $0 \%$ & $100 \%$ & 2 & 0,17 & 0,76 & $31 \%$ & 20 & 0,36 \\
\hline $\begin{array}{l}\text { Participo de cursos c eventos na árca ambiental que } \\
\text { são organizados pelos empreendimentos da } \\
\text { Ecosmar. }\end{array}$ & $15 \%$ & $31 \%$ & $23 \%$ & $4 \%$ & $4 \%$ & $23 \%$ & $100 \%$ & 2 & 0,20 & 0,85 & $39 \%$ & 19 & 0,41 \\
\hline $\begin{array}{l}\text { Participo, depois que as associações da Redc } \\
\text { Ecosmar comę̧aram a atuar em Matarandiba, de } \\
\text { projeto(s) na área ambiental. }\end{array}$ & $15 \%$ & $50 \%$ & $12 \%$ & $0 \%$ & $0 \%$ & $23 \%$ & $100 \%$ & 2 & 0,15 & 0,65 & $32 \%$ & 20 & 0,30 \\
\hline $\begin{array}{l}\text { A Vivetur me fez compreender melhor a importância } \\
\text { do respeito aos recursos naturais que temos na ilha. }\end{array}$ & $0 \%$ & $15 \%$ & $46 \%$ & $4 \%$ & $23 \%$ & $12 \%$ & $100 \%$ & 3 & 0,13 & 0,50 & $17 \%$ & 16 & 0,27 \\
\hline
\end{tabular}

Fonte: Elaboração própria com base nos dados da pesquisa (2017).

Nesse particular, a maioria dos respondentes concordam (68\%) que o trabalho realizado pelas organizações proporcionou-lhes mais consciência ambiental. Quando perguntados de maneira específica sobre o defeso, "que visa proteger os organismos aquáticos durante as fases mais críticas de seus ciclos de vida" (MINISTÉRIO DO MEIO AMBIENTE, 2017), parte deles concorda (42\%) e outra parte importante discorda (39\%) sobre a contribuição das organizações nessa conscientização. Não obstante, é possível deduzir que, pelo menos no geral, eles concordam que a atuação desses empreendimentos contribui para uma melhor compreensão da importância do respeito aos recursos naturais, conforme última questão da tabela (concordância de $50 \%$, contra $15 \%$ de discordância). França Filho (2004), Guimarães (2012) e Santana (2011) defendem essa ideia.

Porém, $46 \%$ e $65 \%$ dos respondentes, respectivamente, discordam de que tenham participado de cursos organizados pelos empreendimentos da Rede ou de que a atuação desses empreendimentos tenha resultado na participação deles em projetos na área ambiental.

A última dimensão analisada é a social, a partir dos dados dispostos na Tabela 6:

Tabela 6 - Utilidade Social quanto à dimensão Social

\begin{tabular}{|l|c|c|c|c|c|c|c|c|c|c|c|c|c|}
\hline Questão & DT & D & C & CT & NSR & NSA & Total & $\begin{array}{c}\text { Médi } \\
\text { a }\end{array}$ & Erro & $\begin{array}{c}\text { Desv } \\
\text { io }\end{array}$ & CV & n & $\begin{array}{c}\text { Confiança } \\
\text { (95\%) }\end{array}$ \\
\hline $\begin{array}{l}\text { As as ociações locais poderão, com seu trabalho, } \\
\text { nos ajudar a ter um serviço de água e esgoto melhor. }\end{array}$ & $8 \%$ & $15 \%$ & $46 \%$ & $8 \%$ & $19 \%$ & $4 \%$ & $100 \%$ & 3 & 0,17 & 0,80 & $30 \%$ & 21 & 0,36 \\
\hline $\begin{array}{l}\text { A padaria comunitária me garante, em condições } \\
\text { mais favoráveis, os produtos que antes cu } \\
\text { comprava fora da comunidade. }\end{array}$ & $12 \%$ & $15 \%$ & $50 \%$ & $15 \%$ & $0 \%$ & $8 \%$ & $100 \%$ & 3 & 0,18 & 0,88 & $32 \%$ & 23 & 0,38 \\
\hline $\begin{array}{l}\text { Atualmente, meus filhos e/ou sobrinhos tem } \\
\text { melhores condições de estudo por conta do } \\
\text { trabalho que as associą̧̃es executam }\end{array}$ & $8 \%$ & $16 \%$ & $24 \%$ & $16 \%$ & $8 \%$ & $28 \%$ & $100 \%$ & 3 & 0,25 & 1,00 & $36 \%$ & 16 & 0,53 \\
\hline $\begin{array}{l}\text { Quando cu vejo as apresentações culturais da ilha, } \\
\text { eu tenho mais orgulho de ter nascido ou morar aqui. }\end{array}$ & $4 \%$ & $4 \%$ & $42 \%$ & $46 \%$ & $4 \%$ & $0 \%$ & $100 \%$ & 3 & 0,15 & 0,76 & $23 \%$ & 25 & 0,31 \\
\hline $\begin{array}{l}\text { A partir do surgimento das associąões, minhas } \\
\text { condições de trabalho estão melhores, mais dignas. }\end{array}$ & $12 \%$ & $24 \%$ & $4 \%$ & $4 \%$ & $4 \%$ & $52 \%$ & $100 \%$ & 2 & 0,25 & 0,85 & $43 \%$ & 12 & 0,54 \\
\hline
\end{tabular}

Fonte: Elaboração própria com base nos dados da pesquisa (2017).

Quanto ao acesso a serviços e acesso a produtos, os respondentes em sua maioria acreditam que a atuação das associações locais pode contribuir para a melhoria do sistema de água e esgoto (54\%) e que a padaria comunitária garante produtos em condições melhores do que antes (65\%). Nessa mesma direção, concordam $88 \%$ dos respondentes de que as associações culturais aumentam 0 orgulho de ter nascido e/ou morar na ilha, contribuindo assim para a identificação com a comunidade, o sentimento de pertencimento. Esses resultados encontram respaldo teórico nos trabalhos de Assumpção e Campos 
(2011); Benini e Benini (2015); Caruana e Srnec (2013); França Filho (2004); Guimarães (2012); Kuyven (2016); Laville (2014); Santana (2011); Santos (2016), Sowa, Selden, Sandfort (2004) e Silva Júnior (2016).

Por outro lado, os resultados são inconclusivos no que diz respeito à contribuição delas para a melhoria das condições de trabalho, pois 52\% responderam "Não se aplica" (o que se explica pelo fato de $26 \%$ serem aposentados(as) e $32 \%$ trabalharem em atividades domésticas), restando um percentual menos expressivo (36\%) dos que discordam. Também foi considerada inclusiva a contribuição das organizações para a melhoria nas condições da educação, pois $24 \%$ discordaram, $40 \%$ concordaram e $28 \%$ não souberam responder.

Expostos os resultados para as seis dimensões, apresenta-se no Quadro 02 o modelo de análise deste estudo, no qual na segunda coluna (B) são apresentadas as dimensões, extraídas do referencial teórico (coluna "C"). Na coluna seguinte (D), são apresentadas variáveis relacionadas com cada uma das dimensões e que neste estudo serviram de base para a formulação dos itens do questionário. $\mathrm{Na}$ coluna E, apresentam-se os resultados do estudo empírico, ou seja, se "sim", os beneficiários concordam que as organizações são úteis em relação a cada variável, ou "não".

Quadro 02 - Modelo de Análise do Estudo

\begin{tabular}{|c|c|c|c|c|}
\hline CONCEITO & DIMENSÕES & $\begin{array}{c}\text { AUTORES } \\
\text { (OBJ. ESPECÍFICO I) }\end{array}$ & $\begin{array}{l}\text { VARIÁVEIS } \\
\text { ESPERADAS }\end{array}$ & $\begin{array}{l}\text { BENEFICIÁRIOS } \\
\text { (OBJ. ESPECÍFICO II) }\end{array}$ \\
\hline A & B & C & D & $E$ \\
\hline \multirow{8}{*}{ 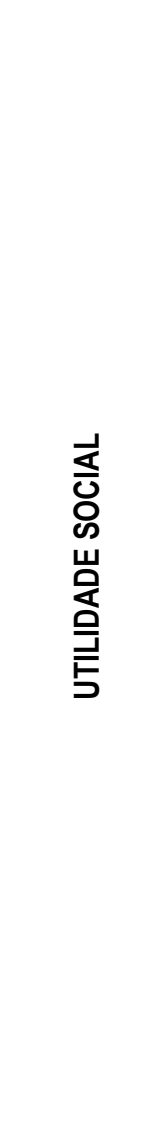 } & Cultural & $\begin{array}{l}\text { Assumpção; Campos (2011); Benini; } \\
\text { Benini (2015); Caruana; Srnec } \\
\text { (2013); França Filho (2004); } \\
\text { Guimarães (2012); Santana (2011), } \\
\text { Silva Júnior (2016). }\end{array}$ & Lazer & Sim \\
\hline & & & Esporte & Não \\
\hline & & & $\begin{array}{l}\text { Manifestações } \\
\text { culturais }\end{array}$ & Sim \\
\hline & Econômica & $\begin{array}{l}\text { Assumpção; Campos (2011); Benini; } \\
\text { Benini (2015); Caruana; Srnec } \\
\text { (2013); França Filho (2004); } \\
\text { Guimarães (2012); Kuyven (2016); } \\
\text { Laville (2014); Santana (2011); } \\
\text { Santos (2016); Sowa, Selden, } \\
\text { Sandfort (2004), Silva Júnior (2016). }\end{array}$ & Renda & Não \\
\hline & & & Emprego & Sim \\
\hline & & & Consumo & Sim \\
\hline & & & Igualdade econômica & Não \\
\hline & Política & $\begin{array}{l}\text { Assumpção; Campos (2011); Benini; } \\
\text { Benini (2015); Caruana; Srnec } \\
\text { (2013); França Filho (2004); } \\
\text { Guimarães (2012); Santana (2011), } \\
\text { Silva Júnior (2016). }\end{array}$ & Representação direta & Não \\
\hline
\end{tabular}




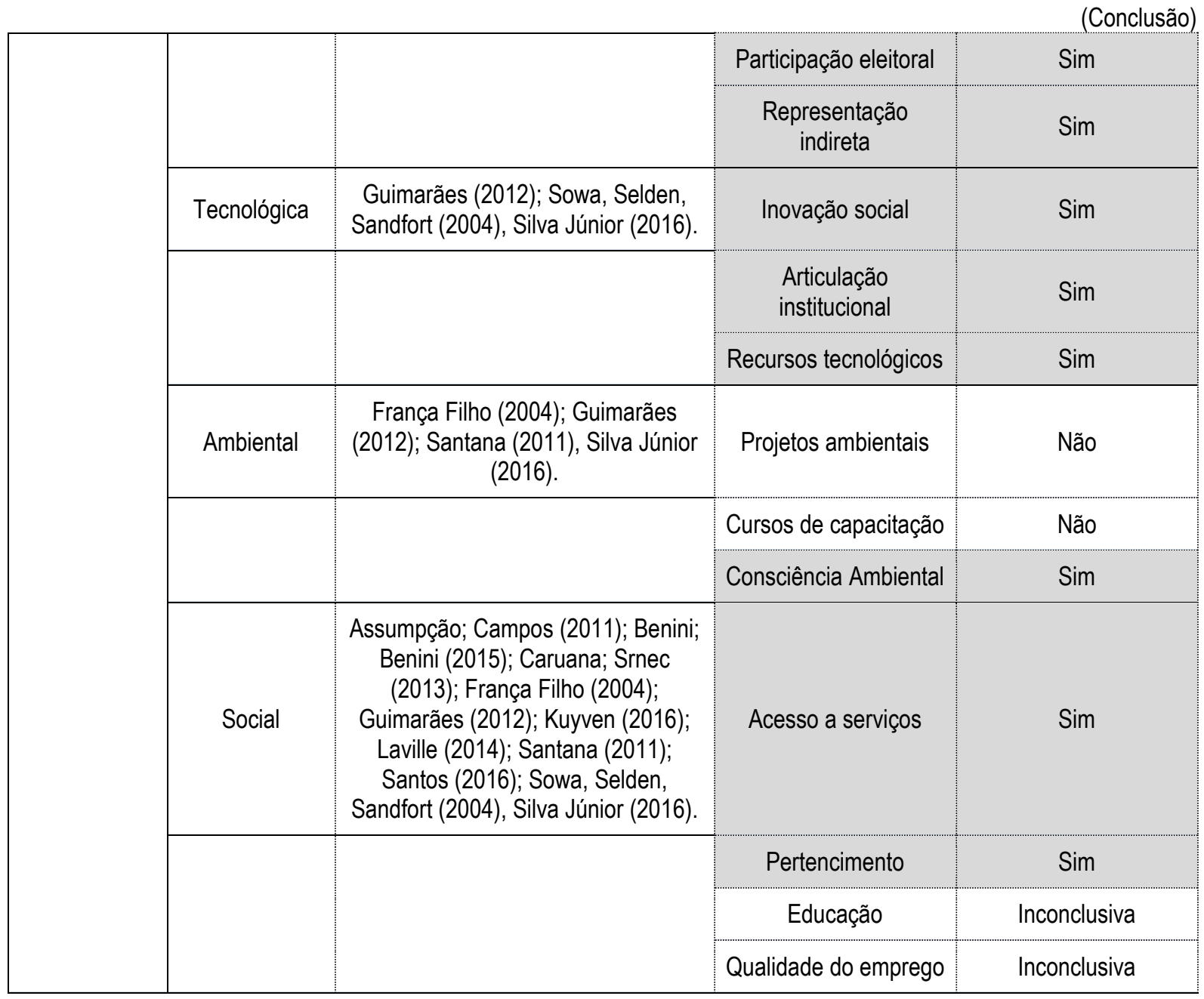

Fonte: Elaboração própria com base nos dados da pesquisa (2017).

Foi verificado por meio dos respondentes, conforme demonstrado ao longo desta seção, quais dessas variáveis (e dimensões, por conseguinte) são apontadas pelos beneficiários como um aspecto de utilidade social das organizações aqui estudadas. Assim, para atingir o objetivo geral deste estudo, de confrontar o exposto na literatura com a percepção dos beneficiários, recorreu-se ao cotejo das colunas "C", "D" e "E", constatando-se as dimensões identificadas tanto pelos teóricos quanto pelos beneficiários (hachuradas).

A partir dos elementos expostos nesse Quadro 2, segundo a percepção dos moradores que participaram desta pesquisa, percebeu-se que a rede de empreendimentos de Matarandiba consegue ser socialmente útil nas variadas dimensões em que essa utilidade se apresenta, conforme a literatura mostra. Contudo, percebeu-se que, para algumas variáveis, a percepção dos moradores é a de que não há contribuição dos empreendimentos da rede. Considerando o contexto de atuação e as características dessas organizações, pode-se fazer algumas análises para além dos dados descritivos, que podem contribuir para o entendimento desse cenário.

Um dos aspectos é o fato de os empreendimentos da rede, com os mais variados focos de atuação, surgirem em momentos distintos. Por exemplo, a associação Ascoma, que trata de aspectos gerais relacionados com os direitos dos moradores de Matarandiba, já existia antes mesmo do surgimento do Projeto Ecosmar, sendo reestruturada em 2007. Enquanto isso, outros empreendimentos/projetos só surgiram posteriormente, como o Banco Comunitário e a Ascomat (com foco em projetos culturais), que só iniciaram suas atividades em 2008 , ou a ostreicultura familiar, iniciada em 2011, e a Vivertur (na área de turismo de base comunitária), surgida em 2013, ou ainda a padaria comunitária, projeto de 2015. 
Como essas entidades possuem objetivos específicos, cada uma delas focada em determinado aspecto relacionado com a utilidade social que aqui se analisou, o fato de elas surgirem em momentos distintos faz com que os resultados dessas também sejam alcançados de forma variada. É, portanto, natural que os objetivos da padaria comunitária sejam alcançados posteriormente aos da Ascomat, por exemplo.

Outro elemento é o fato de as primeiras capacitações realizadas pela incubadora universitária só terem ocorrido em 2011. Segundo Silva e Oliveira (2011), a atuação das incubadoras tem efeito significativo sobre o desenvolvimento dessas organizações da sociedade civil, por consequência, para que elas possam alcançar mais plenamente seus objetivos institucionais, resultado em utilidade social. Logo, só à medida que as capacitações realizadas pela incubadora vão se realizando, é que o alcance, a utilidade social dela é mais destacada.

Contudo, não se pode descartar e convidar as organizações de Matarandiba e de outras localidades, a necessidade de refletir sobre a possibilidade de elas não estarem atuando de modo satisfatório em alguma das variáveis ou mesmo em alguma dimensão de modo integral.

\section{CONSIDERAÇÕES FINAIS}

Conforme demonstrado no modelo de análise deste estudo, apresentado ao final da seção anterior, muitas dentre as variáveis encontradas na literatura acerca do que caracteriza e qualifica a utilidade social das organizações da sociedade civil foram confirmadas pelos respondentes. A partir das análises das respostas e das observações, concluiu-se que a atuação das organizações da sociedade civil localizadas em Matarandiba resulta em um quadro que demonstra a utilidade social destas para os moradores dessa comunidade no que se refere a variáveis relacionadas com as dimensões do Quadro 2 aqui consideradas.

Quanto à dimensão cultural, destaca-se a contribuição para a melhoria dos espaços para atividades de lazer e quanto à realização de manifestações culturais. Na dimensão econômica, são evidentes que as ações das organizações influenciam a geração de relações entre as pessoas que acabam viabilizando emprego, além do fomento ao consumo local. Na perspectiva da dimensão política, as organizações são importantes para a representação indireta e para o fortalecimento da participação eleitoral. Na dimensão tecnológica, concordaram que há influência em todas as variáveis propostas: inovação social; articulação institucional e recursos tecnológicos. Por outro lado, das três variáveis presentes na dimensão ambiental, a contribuição para a conscientização foi o único impacto percebido. $\mathrm{Na}$ última dimensão analisada, a social, os respondentes atribuem à atuação das organizações a melhoria do acesso a serviços e do espírito de pertencimento ao território.

Contudo, os resultados não confirmam a percepção dos beneficiários no que diz respeito à realização de atividades esportivas (dimensão cultural); ao aumento de renda pessoal e/ou da família (econômico), o que reforça a ideia de que essas organizações, pelas suas características, pouco têm contribuído nesses aspectos. Também não concordam que as organizações impliquem representação direta (política), nem contribuam no que diz respeito à realização de cursos e projetos relacionados com a dimensão ambiental. Na dimensão social, não foi possível encontrar resultados conclusivos no que diz respeito à melhoria nas condições de educação e na qualidade do emprego.

É preciso dizer que, apesar de todos os cuidados no sentido de garantir a condução deste estudo a partir de uma amostra aleatória probabilística que permitisse a obtenção de inferências estatísticas para a sua população, os seus resultados se referem sobretudo à amostra analisada, já que o número de respondentes alcançado foi pequeno. Em pesquisas futuras do tipo, especialmente em comunidades tradicionais como a aqui analisada, é preciso cuidar para que o tempo de realização da aplicação dos questionários seja rigorosamente seguido, o que requer bastante perspicácia de quem os esteja aplicando. $O$ cuidado dos respondentes em justificar ao máximo as suas respostas, apesar da utilização de questionário estruturado, foi o fator que contribuiu para tal delonga e, por consequência, para o alcance de respondentes em número inferior do que o desejado inicialmente. 
Com o questionário planejado para este estudo, a pretensão inicial era a realização do exame via técnica de Análise Fatorial, em busca de sua validação como escala para medir a percepção de beneficiários sobre a utilidade social das organizações da sociedade civil. Contudo, como a recomendação é que se tenha uma amostra formada por, no mínimo, cinco indivíduos para cada item do questionário (FIELD, 2009), seria preciso uma amostra de pelo menos 150 respondentes, o que foi planejado, mas, infelizmene, não foi alcançado, o que se caracterizou em uma limitação desse estudo. Desse modo, estudos futuros podem partir das questões aqui utilizadas, considerando inclusive os parâmetros estatísticos calculados conforme as respostas neste obtidas, demonstrados nas tabelas 2 a 7, e promover ajustes na sua apresentação ou reformulação das questões, buscando a ampliação da amostra para tentar a validação deste como escala.

Considerando que o Novo Marco Regulatório dessas organizações prevê a avaliação das parcerias a partir da percepção dos beneficiários, uma escala como essa, iniciada a partir deste estudo, é uma importante contribuição prática para tal intento. Esse aspecto torna as contribuições tanto prática quanto teórica desse estudo mais claras, na leitura dos pesquisadores desta investigação. Vale lembrar que este estudo é apenas um primeiro passo na sistematização de indicadores ou metodologias para avaliação da utilidade social de organizações sociais e é parte de uma pesquisa mais ampla de um programa de estudos aplicados dentro de um núcleo de pesquisa recentemente criado.

Nesse sentido, com esta pesquisa, colaborou-se com empreendimentos da sociedade civil, bem como com aqueles que estejam interessados em sua atuação, como organismos nacionais e internacionais de fomento, entes públicos ou incubadoras universitárias, por revelar variáveis que não são percebidas por potenciais beneficiários como resultado da atuação delas. Ademais, também se avançou na confirmação do que é relatado por outros estudos sobre o tema, por meio de uma imersão à realidade, demonstrando variáveis vinculadas a seis dimensões da utilidade social dessas organizações, a saber: Cultural, Econômica, Política, Tecnológica, Ambiental e Social.

\section{REFERÊNCIAS}

ASSUMPÇÃO, J.; CAMPOS, L. Avaliação de projetos sociais em ONGs da Grande Florianópolis: um estudo sobre modelos relacionados ao foco de atuação. Revista de Administração Pública, p. 209242, jan./fev. 2011.

BENINI, E. A.; BENINI, E. G. As Contradições do Processo de Autogestão no Capitalismo: funcionalidade, resistência e emancipação pela economia solidária. Revista O\&S, Salvador, v. 17, n. 55, p. 605-619, Out./Dez. 2010.

A Construção do Trabalho Associado Sob a Hegemonia Estatal: Organização, Solidariedade e Sociabilidade. Revista O\&S, Salvador, v. 22, n. 74, p. 325-344, jul./set. 2015.

BRASIL. Lei $n^{0}$ 13.019, de 31 de julho de 2014. Estabelece o regime jurídico das parcerias entre a administração pública e as organizações da sociedade civil, e dá outras providências. Brasília, DF, 2014. Disponível em: http://www.planalto.gov.br/ccivil_03/_ato2011-2014/2014/lei//13019.htm. Acesso em: 16 abr. 2017.

CAMPOS, L.; ANDION, M. C. Avaliação de Projetos Sociais em Organizações da Sociedade Civil: Um Estudo sobre Concepções e Práticas. In: XXXV Encontro da ANPAD, 35., 20011. Anais... Rio de Janeiro: ANPAD, 2011.

CARUANA, M. E. C.; SRNEC, C. C. Public Policies Addressed to the Social and Solidarity Economy in South America. Toward a New Model? Voluntas, n. 24, p. 713-732, 2013.

CAUQUIL, G. Avant-propos: apprécier l'utilité sociale, un enjeu sensible pour leSFE. In: OFFREDI, C.; RAVOUX, F. (Orgs.) La notion d'utilité sociale au defi de son identité dans l'évaluation des politiques publiques. Paris: L'Harmattan, 2010. p. 11-12. 
DUCLOS, H. Évaluer l'utilité sociale de son activité: conduire une démarche d'auto-évaluation. Paris: Édition Baton Rouge/Polyprint Édition, Collection Les Cahiers de Avise, 2007.

Quels enseignements tirer de l'évaluation de l'utilité sociale dans le secteur de l'économie sociale et solidaire? In: OFFREDI, C.; RAVOUX, F. (Orgs.). La notion d'utilité sociale au defi de son identité dans l'évaluation des politiques publiques. Paris: L'Harmattan, 2010. p. 57-77.

FAVERO, L. P; BELFIORE, P.; SILVA, F. L.; CHAN, B. L. Análise de dados: modelagem multivariada para tomada de decisões. Rio de Janeiro: Campus Elsevier, 2009.

FERES FARIA, C. Estado e organizações da sociedade civil no Brasil contemporâneo: construindo uma sinergia positiva?. Revista de Sociologia e Política, v. 18, n. 36, p. 187-204, 2010.

FIELD, A. Descobrindo a estatística usando o SPSS. 2. ed. Porto Alegre: Artmed, 2009.

FONSECA, C.; OLIVEIRA, A.; RODRIGUES, M. C. Avaliação de Projeto Social em Organização do Terceiro Setor. Revista da Universidade Vale do Rio Verde, Três Corações, v. 14, n. 2, p. 1184-1200, ago./dez., 2016.

FRANÇA FILHO, G. C. de. A problemática da economia solidária: um novo modo de gestão pública? Cadernos EBAPE.BR, v. 2, n. 1, mar. 2004.

GADREY, J. L'utilité sociale des organisations de l'économie sociale et solidaire: une mise en perspective sur la base de travaux récents: rapport de synthèse pour la DIES et la MIRE. Lille: CLERSE-IFRESI/Université de Lille 1, 2004. 136p.

Utilité sociale. In: CATTANI, A.; LAVILLE, J.-L. (Org.). Dictionaire de l'autre économie. 1. ed. Paris: Desclée de Brouwer, 2005. p. 517-524.

GAIGER, L. A Economia Solidária diante do Modo de Produção Capitalista. Caderno CRH, Salvador, n. 39, p. 181-211, jul./dez. 2003.

GRAMSCI, A. Os Intelectuais e a Organização da Cultura. Rio de Janeiro: Civilização Brasileira, 1968. $244 \mathrm{p}$.

GUIMARÃES, A. de M. Incubação de Redes Locais de Economia Solidária: Contribuições para um Desenho Avaliativo do Caso Matarandiba - Um Relato de Experiência. 108 f., 2012. Dissertação (Mestrado) - Universidade Federal da Bahia, Núcleo de Pós-Graduação em Administração, Salvador, BA, 2012.

JANY-CATRICE, F. et al. Evaluer l'utilité sociale de l'Economie Sociale et Solidaire. Lille: APES, 2014. 43 p.

KUYVEN, P. S. Efeitos da Economia Solidária sobre a Geração de Renda e a Redução da Probreza: um estudo de dados nacionais. 249 f., 2016. Tese (Doutorado) - Universidade do Vale do Rio dos Sinos, Programa de Pós-Graduação em Ciências Sociais, São Leopoldo, RS, 2016.

LAVILLE, J. L. Trabalho e socioeconomia, In. Cattani (Org.). Trabalho: horizonte 2021. Porto Alegre: Escritos Editora, 2014. p. 167-178.

MAURER, L. L. Board Member Perceptions of Small Nonprofit Organization Effectiveness. Journal of Social, Behavioral, and Health Sciences, v. 10, n. 1, p. 18-30, 2016.

MINISTÉRIO DO MEIO AMBIENTE. Períodos de defeso. Disponível em: <http://www.mma.gov.br/ biodiversidade/biodiversidade-aquatica/recursos-pesqueiros/per\%C3\%ADodos-de-defeso>. Acesso em: 24 abr. 2017.

MITCHELL, G. E.; BERLAN, D. Evaluation and Evaluative Rigor in the Nonprofit Sector. Nonprofit Management \& Leadership, v. 27, n. 2, 2016. 
OFFREDI, C. Itinéraire d'un questionnement de la notion d'utilité sociale en matière d'évaluation des politiques publiques. In: OFFREDI, C.; RAVOUX, F. (Orgs.). La notion d'utilité sociale au defi de son identité dans l'évaluation des politiques publiques. Paris: L'Harmattan, 2010. p. 31-43.

PERRET, B. Utilité sociale, évaluation et nouvelle conception de gouvernance. In: OFFREDI, C.; RAVOUX, F. (Orgs.) La notion d'utilité sociale au defi de son identité dans l'évaluation des politiques publiques. Paris: L'Harmattan, 2010. p. 45-50.

POLANYI, K. A grande transformação: as origens de nossa época. Tradução de Fanny Wrabel. 2. ed. Rio de Janeiro: Compus, 2000.

PROJETO ECOSMAR. Rede Ecosmar. Disponível em: <https://projetoecosmar.wordpress.com/a-redeecosmar/>. Acesso em: 23 de abr. 2017.

QUIJANO, A. Sistemas alternativos de produção? In: SANTOS, B. de S. Produzir para Viver: os caminhos da produção não capitalista. 2. ed. Rio de Janeiro: Civilização Brasileira, 2005.

RIGO, A. S. Moedas Sociais e Gestão de Territórios: Aplicações e Implicações Teóricas e Práticas. 344f., 2014. Tese (Doutorado) - Universidade Federal da Bahia, Núcleo de Pós-Graduação em Administração, Salvador, BA, 2014.

RIGO, A. S.; FRANÇA FILHO, G. C. de. Bancos comunitários e moedas sociais no Brasil: reflexões a partir da noção de economia substantiva. Salvador: EDUFBA, 2017.

RIGO, A. S.; FRANÇA FILHO, G. C. de.; LEAL, L. P. Moedas Sociais nos Bancos Comunitários de Desenvolvimento: a Experiência das Conchas em Matarandiba/BA. RIGS Revista Interdisciplinar de Gestão Social. v. 4, n. 2, mai./ago. 2015.

ROSSO, S. D. A jornada de trabalho na sociedade. São Paulo: LTR editora, 1996.

SANTANA, C. A. de. Bancos Comunitários de Desenvolvimento e 0 apoio à Promoção do Desenvolvimento Local: O Caso do Banco Ilhamar. 144 f., 2011. Dissertação (Mestrado) Universidade Federal da Bahia, Núcleo de Pós-Graduação em Administração, Salvador, BA, 2011.

SANTOS, D. P. dos. Stakeholders e o Desempenho Social Corporativo de Entidades Desportivas do Terceiro Setor: Proposta de Mensuração. 102 f, 2016. Dissertação (mestrado) - Universidade Nove de Julho - UNINOVE, São Paulo, SP, 2016.

SANTOS, B. de S.; RODRÍGUEZ, C. Para ampliar o cânone da produção. In: SANTOS, B. de S.; RODRÍGUEZ, C. Produzir para Viver: os caminhos da produção não capitalista. 2. ed. Rio de Janeiro: Civilização Brasileira, 2005.

SILVA, M. K; OLIVEIRA, G. de L. A face oculta(da) dos movimentos sociais: trânsito institucional e intersecção Estado-Movimento - uma análise do movimento de Economia Solidária no Rio Grande do Sul. Sociologias, Porto Alegre, v. 13, n. 28, p. 86-124, set./dez. 2011.

SILVA JÚNIOR, J. T. Utilidade social e finanças solidárias: uma proposta de avaliação dos bancos comunitários de desenvolvimento brasileiros. 291f., 2016. Tese (Doutorado) - Universidade Federal da Bahia, Núcleo de Pós-Graduação em Administração, Salvador, BA, 2016.

SILVA JÚNIOR, J. T.; FRANÇA FILHO, Genauto Carvalho de ; RIGO, A. S. Coesão Territorial Através da Aliança Comunidade e Poder Pública na Execução de Políticas Públicas de Economia Solidária no Brasil: A Utilidade Social dos Bancos Comunitários de Desenvolvimento. In: VI Congreso Internacional en Gobierno, Administración y Politicas Públicas - GIGAPP, 6., 2015, Madri. Anais... Madri: GIGAPP, 2015.

SILVA JÚNIOR, J. T.; RIGO, A. S; PASSOS, O. A. V. D. Gestão Social nas Finanças Solidárias: Reflexões sobre a Avaliação da Utilidade Social dos Bancos Comunitários de Desenvolvimento no Brasil. Revista NAU Social, Salvador, v. 6, n.10, p. 151-164, mai./out., 2015.

SINGER, P. Introdução à economia solidária. São Paulo: Ed. Perseu Abramo, 2002. 
SOWA, J. E.; SELDEN, S. C.; SANDFORT, J. R. No longer Unmeasurable a Multidimensional Integrated Model of Nonprofit Organizational Effectiveness. Nonprofit and Voluntary Sector Quarterly, v. 33, n. 4, p. 711-728, dez. 2004.

TOSCANO, I. O Banco PALMA\$: uma experiência de economia solidária Fortaleza/CE. In: FRANÇA, C. L. de; VAZ, J. C.; SILVA, I. P. (Org.). Aspectos econômicos de experiências em desenvolvimento local. São Paulo: Instituto Pólis, 2002.

VERGARA, S. C. Projetos e relatórios de pesquisa em administração. 12. ed. São Paulo: Atlas, 2010.

¡ Trata-se dos Acórdãos do Conselho de Estado da França, n 85586 e n 85598, publicados em 30 de novembro de 1973, relativos à decisão do processo chamado 'La clinique saint $L u c$ ', referindo-se à revisão dos critérios para a isenção de impostos a negócios que se limitam a uma exploração ou operação de caráter não lucrativo. Informações disponíveis em: <https://www.legifrance.gouv.fr/affichJuriAdmin.do?idTexte=CETATEXT000007613368> $<$ <ttps://www.legifrance.gouv.fr/affichJuriAdmin.do?idTexte=CETATEXT000007613370>. 